\title{
A INVESTIGAÇÃO CIENTÍFICA NO CURSO DE ENFERMAGEM: UMA ANÁLISE CRÍTICA
}

\author{
Scientific Research at Nursing Course: \\ The Critical Analyses \\ La Investigación Científica en el Curso de Enfermería: \\ Un Análisis Crítico
}

lací Proença Palmeira ${ }^{1}$

Mirta Betancourt Rodriguéz $z^{2}$

\begin{abstract}
Resumo
Pesquisa qualitativa que objetivou diagnosticar a formação de habilidades investigativas no Curso de Enfermagem da Universidade do Estado do Pará em 1999. A amostra foi de 42 alunos e 10 professores. Para a coleta de dados, foram utilizados a entrevista semi-estruturada e o questionário, cujas respostas foram submetidas à análise de conteúdos, gerando duas categorias temáticas. Os resultados demonstraram que o curso não propicia o desenvolvimento das aptidões investigativas, porque os alunos não são motivados; o ensino é tecnicista e não ressalta o componente investigativo; os trabalhos realizados pelos alunos são desprovidos de rigor científico; e a maioria dos professores apresenta inconsistente formação científico-investigativa para aplicar técnicas de ensino-aprendizagem que possibilitem seu alcance. Concluiu-se que as habilidades investigativas constroem-se em múltiplas vias, sendo necessário, em primeiro lugar, explorar e estimular o gosto pela investigação nos professores e nos alunos, para que essa atividade converta-os em eternos aprendizes da prática investigativa.
\end{abstract}

Palavras-chave: Pesquisa. Enfermagem. Motivação. Educação.

\begin{abstract}
Qualitative research, with the objective to diagnose the formation of search into abilities in the Nursing Course at the Pará State University in 1999. The sample was 42 pupils and ten professors. For the collect of data, was use half structurized interview and the questionnaire whose answers had been submitted the analysis of contents, generating two thematic categories. The results had demonstration that the course does not propitiates the development of the investigative acquirement, because the pupils are not motivate, education is technicality and not arrange the investigative component; The works carried through for the pupils are unprovided of scientific severity; the majority of the professors presents unconsciously investigative scientific formation to apply exercise of teach-learning to possibility obtaiment. It is concluded that the investigative abilities construct in multiple ways, been necessary, in first place, to explore and to stimulate the taste for the enquire in the professors and pupils, making this activity proselytize them perpetual apprentices in investigative practices.
\end{abstract}

Keywords:

Research. Nursing. Motivation. Education.

\section{Resumen}

Investigación cualitativa, que tuvo por objetivo: diagnosticar la formación de habilidades investigativas en el Curso de Enfermería de la Universidad del Estado do Pará en 1999. La muestra fue de 42 alumnos y 10 profesores. Para la colecta de los datos se utilizaron la entrevista semi-estructurada y el cuestionario, cuyas respuestas fueron sometidas al análisis de los contenidos, generando dos categorías temáticas. Los resultados demostraron que el curso no propicia lo desarrollo de las aptitudes investigativas, porque los alumnos no son motivados; la enseñanza es técnica y no resalta lo componente investigativo; los trabajos realizados por los alumnos son desprovistos de rigor científico; la mayoría de los profesores, no poseen la formación para la investigación y para aplicar técnicas de enseñanza-aprendizaje que posibiliten su alcance. Se concluye que las habilidades investigativas se construyen por varios medios, siendo necesario, en primero lugar, explotar y estimular el gusto por la investigación en los profesores y alumnos, para que esa actividad los convierta en eternos aprendices de la práctica investigativa.

Palabras clave:

Investigación. Enfermeria. Motivación. Educación.

${ }^{1}$ Enfermeira. Mestre em Educação. Especialista em Saúde Pública. Membro do Grupo de Pesquisa-Intervenções de Enfermagem no Processo Saúde-Doença da Universidade do Estado do Pará (UEPA). Professora Assistente IV do Departamento de Enfermagem Comunitária da UEPA. E-mail: iaci_palmeira@yahoo.com.br. ${ }^{2}$ Professora Orientadora. Doutora em Educação do Instituto Félix Varela. Santa Clara - Cuba. 


\section{CONSIDERAÇÕES INICIAIS}

Este artigo é um recorte da dissertação de mestrado intitulada "A investigação científica no Curso de Enfermagem da Universidade do Estado do Pará: da análise à proposta"1.

Trata-se de um estudo centrado na carência de investigação cientifica por parte dos alunos e professores daquela instituição e na razão de essa atividade limitar-se a Trabalhos de Conclusão de Curso (TCC), seja de graduação ou de pós-graduação, dos quais não se tem uma avaliação qualitativa, uma vez que normalmente se consegue computar quantidades, mas pouco se discute a relevância social e a qualidade acadêmica do objeto desses trabalhos.

Esse cenário não é o desejado para a profissão, pois a sociedade paraense necessita de enfermeiros críticos e reflexivos, capazes de transformar a prática em uma constante construção de novos conhecimentos, fazendo da Amazônia uma fonte inesgotável de indagações e investigações que venha a elevar, cada vez mais, o nível de formação e o poder de transformação do enfermeiro, assim como do status quo da instituição.

Por outro lado, a globalização da economia exige enfermeiros com um perfil profissional que lhes possibilite construir sua própria cultura, seu corpo de conhecimentos e habilidades, divulgar seus resultados e romper paradigmas teóricos, imprimindo à profissão um caráter humanista e social, e não somente tecnicista.

A partir dessa visão e com arrimo na Lei de Diretrizes e Bases da Educação Brasileira ${ }^{2}$, existe a necessidade de associar o ensino e a investigação: o ensinar investigando, o investigar ensinando e o ensinar a investigar.

Nesse contexto, a universidade precisa formar enfermeiros críticos, buscando melhorias para os problemas sociais, educacionais, sanitários e econômicos, por meio de financiamentos concedidos à investigação. É preciso elevar o nível de formação do enfermeiro e o seu poder de transformação da realidade, assim como do status quo da instituição.

A autora, como enfermeira e professora, responsável, até certo ponto, pela formação desse profissional, sentiu-se mobilizada ante a necessidade de entender como vinha sendo processada a formação de habilidades investigativas no Curso de Enfermagem da UEPA, ao constatar as deficiências dos alunos no momento da elaboração dos seus TCCs, manifestadas na dificuldade de indagar, descrever, interpretar e problematizar a realidade.

Nesse exato ponto, centrou-se a inquietação, pois, ao final do curso, quase nada mais poderia ser feito para superar essas dificuldades tardiamente detectadas. Diante do exposto, adotou-se como problema de investigação o seguinte: Como vem sendo processada a formação das habilidades investigativas no Curso de Enfermagem da UEPA?

Constituiu-se objeto de estudo a formação de habilidades investigativas no Curso de Graduação em Enfermagem da Universidade do Estado do Pará (UEPA).

A investigação objetivou diagnosticar a formação de habilidades investigativas nesse Curso.

0 estudo teve como referencial a Teoria da Atividade de Alexei Nikolaevich Leontiev ${ }^{3}$, bem como autores que buscam, no materialismo histórico-dialético, a solução para problemas teóricos ligados ao estudo do desenvolvimento dos processos mentais humanos ${ }^{4,5,6,7,7,9,10,11}$.

\section{A ATIVIDADE E O DESENVOLVIMENTO DE HABILIDADES}

Leontiev ${ }^{3}$ apoiou-se no materialismo histórico para explicar como devem ser mediadas as atividades pedagógicas, sempre enfocando que estas devem prever a participação ativa dos sujeitos no processo ensino-aprendizagem. Para ele, "os processos psicológicos superiores específicos do homem podem nascer unicamente da interação do homem com o homem" ${ }^{12: 78}$. Ou seja: o sujeito é resultado de sua própria atividade, por meio de instrumentos e signos, e esse processo é histórico, social e cultural.

As atividades humanas diferem-se por várias razões, mas 0 que distingue uma atividade de outra é seu objeto, isto é, " $O$ objeto da atividade é seu motivo real's:83. Uma necessidade só pode ser satisfeita quando encontra um objeto, e isso se chama "motivo". 0 motivo é o que impulsiona uma atividade, pois integra uma necessidade a um objeto. Objetos e necessidades isolados não produzem atividades. Estas só existem se houver motivos.

Nesse passo, necessidade, objeto e motivo são componentes estruturais da atividade. Além deles, a atividade se constitui em um conjunto de ações subordinadas aos objetivos parciais, advindos do objetivo geral. Assim como a atividade tem relação com o motivo, as ações se relacionam com os objetivos.

Esse processo transita por momentos de motivação e interesses, para que se produza a interação reflexiva entre 0 professor e 0 aluno (entre sujeitos), e do aluno para com os conteúdos que deve assimilar (relação sujeito-objeto). 0 professor direciona o processo ensino-aprendizagem, expressando os conhecimentos e as habilidades que os alunos devem adquirir; estes aprendem na dependência de como se organiza tal processo, apossando-se dos conteúdos e transformando a necessidade em motivo ${ }^{11}$.

De acordo com essa orientação, pode-se entender que o papel de qualquer instituição de ensino é o de facilitar, orientar, problematizar, questionar, motivar e mediar a aprendizagem, e, através da mediação, conduzir o aluno a perceber os motivos e as finalidades pelos quais é importante aprender determinados conteúdos. Ou melhor, levá-los a compreender onde vão utilizar (na vida, como indivíduos/cidadãos) o que estão aprendendo.

Desse modo, o aluno deve realizar tarefas como: observar, descrever o observado e analisar, o que ocorre quando manipulam os diversos materiais postos ao seu alcance com um determinado propósito. Deve também gerar hipóteses, a partir da análise do observado (empírico), realizar várias técnicas relacionadas ao que busca responder, refletir sobre 0 que fez e, ao final, estabelecer algumas conclusões.

Cabe ressaltar, então, que cada tarefa apontada demanda o desenvolvimento de certas habilidades que estejam a seu alcance e que, de modo geral, podem ser consideradas como habilidades relacionadas com a investigação científica, ou seja, habilidades investigativas.

Para efeito deste trabalho, consideraram-se a formação e o desenvolvimento de habilidades investigativas como um processo que envolve práticas diversas, com a intervenção dos formadores como mediadores, concretizando e facilitando, de maneira sistematizada, o acesso aos conhecimentos, 0 
desenvolvimento de habilidades, hábitos e atitudes, e a conscientização de valores que demandem a realização da prática investigativa.

Vale esclarecer que as habilidades investigativas são habilidades cognitivas e permitem associar situações antigas com aquilo que se espera que venha a acontecer, propiciando a explicação, a previsão e a identificação de causas, efeitos, fins, meios e conseqüências. É através das mesmas que se aprende a formular problemas, estimar, medir, constatar e desenvolver as inúmeras capacidades formadoras da prática que se associam ao processo de investigação ${ }^{13}$.

Admite-se que as habilidades investigativas dotam 0 sujeito do instrumental necessário para a utilização e aplicação do sistema de conhecimentos das atividades que permitam investigar a realidade, problematizar, desvelar, descrever, conjecturar, planificar, executar, diagnosticar, propor intervenções, experimentar, produzir novos conhecimentos e comunicar os resultados.

Portanto, compreender a formação e o desenvolvimento das habilidades investigativas, à luz da teoria da atividade de Alexei Nikolaevich Leontiev ${ }^{7}$, requer entender que essas habilidades têm como característica essencial o predomínio de ações psíquicas e práticas que, conscientemente, permitem a execução de uma atividade com êxito, a partir do auxílio de conhecimentos e habilidades previamente desenvolvidos, os quais norteiam 0 indivíduo na seleção das vias mais adequadas para sua consecução.

\section{METODOLOGIA DO ESTUDO}

0 estudo aqui desenvolvido foi do tipo qualitativo, descritivo, com enfoque no materialismo histórico e dialético ${ }^{14}$. Como cenário, o Curso de Enfermagem da Universidade do Estado do Pará, localizado no município de Belém, no ano de 1999.

Os sujeitos do estudo foram 42 alunos matriculados na $5^{\text {a }}$ série do Curso de Enfermagem da Universidade do Estado do Pará e 10 (dez) professores. Estes, além da docência e orientação de TCC, encontravam-se ligados diretamente à gestão administrativa e metodológica do Curso e aceitaram participar desse estudo.

Optou-se por alunos da quinta série por ser a última do Curso e estar atrelada à elaboração do TCC, além de ser nesse período que as dificuldades, decorrentes do não-desenvolvimento das habilidades investigativas nos anos anteriores, manifestamse com maior intensidade, fato este que propiciou uma valorização maior das respostas ao questionário.

A coleta de dados foi realizada no mês de julho de 1999. Para realizar o diagnóstico dos alunos, elaborou-se um questionário com nove perguntas mistas, tendo por objetivos identificar a motivação do aluno para investigar, o nível de reflexão sobre a questão da investigação no Curso e o estado de satisfação com o processo ensino-aprendizagem oferecido.

Com os professores, utilizou-se a técnica da entrevista semiestruturada, visando conhecer o saber advindo da experiência profissional em relação às habilidades investigativas, suas concepções, percepções e critérios de valorizações a respeito do curso, principalmente no que tange à formação profissional.

Desse modo, no que diz respeito aos professores, estabeleceu-se um contato inicial com o entrevistado para explicar o objetivo do estudo, a necessidade de colaboração e o caráter sigiloso do estudo. Em seguida, pediu-se autorização para utilizar o gravador como registro das falas, reproduzidas ao final de cada entrevista, para que o professor pudesse corrigir o que poderia suscitar dúvidas. Após serem transcritas, as entrevistas foram entregues aos professores no intuito de que estes verificassem a presença de erros de interpretação que pudessem alterar o sentido de seus depoimentos.

Os dados foram organizados e tratados após a transcrição e a leitura. Posteriormente, os procedimentos foram agrupados por palavras-chaves e categorizados, conforme a frequência e a intencionalidade com que apareciam nas respostas, seguindo os critérios da análise de conteúdo, sob a ótica de Minayo ${ }^{15}$, originando duas categorias temáticas.

Confrontaram-se os achados com a literatura sobre o tema, com vistas a discutir os resultados até a compreensão do fenômeno, aqui estudado à luz do referencial teórico que arrimou o estudo, ou seja, a teoria da atividade de Alexei Nikolaevich Leontiev³.

Relativamente aos aspectos éticos, vale ressaltar que o estudo não foi submetido à aprovação do Comitê de Ética por não ser uma exigência do Instituto Pedagógico LatinoAmericano e Caribeño. Porém, os objetivos do estudo foram devidamente esclarecidos aos discentes e docentes com as orientações sobre o sigilo das informações por eles prestadas e a utilização de seus resultados somente em trabalhos científicos, divulgados em eventos e periódicos.

Cabe ainda destacar que tanto discentes quanto os docentes foram informados da total liberdade de participar ou não como sujeitos do estudo e que tal opção não geraria nenhuma forma de punição ou prejuízo; bem como poderiam retirar-se do mesmo a qualquer momento, com a garantia de entrega de seus depoimentos na hora em que o solicitassem.

\section{RESULTADOS E DISCUSSÃO}

Os dados obtidos no questionário realizado com os alunos originaram duas grandes categorias temáticas:

- Categoria I: Percepção quanto ao valor e utilidade de se executar uma atividade e a projeção do modo de atuar com o conhecimento daí advindo;

- Categoria II: A motivação do aluno para investigar.

\section{I - A percepção quanto ao valor e utilidade de se executar uma atividade e a projeção do modo de atuar com o conhecimento daí advindo}

Trata-se de uma categoria relativa à opinião dos alunos quanto à importância de realizarem trabalhos científicos na vida acadêmica. A análise das respostas complementares evidenciou a falta de exatidão nos critérios valorativos expressados, originando três subcategorias de análise: Ausência de reflexão, Reflexão média e Reflexão boa.

\section{Ausência de reflexão:}

Os alunos inseridos nesta subcategoria se limitaram a reproduzir informações, não manifestando valorizações específicas em suas respostas. Incluíram-se aqui onze alunos, exemplificados com: 
[...] Acharia muito importante que tais aspectos fossem trabalhados durante o curso $[. .].\left(A_{5}, A_{11}, A_{15}, A_{21}\right.$ e $\left.A_{32}\right)$.

[...] Acho muito importante, pois estimularia o interesse pela pesquisa $[. .].\left(A_{4}, A_{7}, A_{12}\right)$.

A percepção do valor de uma atividade significa o juízo emitido pelo aluno sobre a sua utilidade, com vistas a alcançar os objetivos que persegue ${ }^{16}$. Pode-se então dizer que depende das metas que o discente almeja e dos critérios para se posicionar com suporte reflexivo e estabelecer relações afetivas, condicionados pelas necessidades pessoais, profissionais e outras.

Merece atenção o fato de 18 alunos terem feito vinculação temática exclusiva ao TCC, o que reflete ser este o único e último ensaio investigativo do curso, conforme evidenciado a seguir:

[...] Acho muito importante para o aluno se familiarizar com o TCC $[. .].\left(A_{14}, A_{26}, A_{30}, A_{39}\right)$.

[...] Incentivaria o interesse pela investigação no curso e facilitaria a elaboração do TCC $[. .].\left(A_{19}, A_{28}, A_{38}\right)$.

o Curso de Enfermagem prepara apenas enfermeiros, investigação, aqui, é só o TCC [...] $\left(A_{31}\right)$.

É consenso que a aprendizagem reprodutiva limita o vínculo científico de qualquer atividade. Portanto, o desenvolvimento de trabalhos científicos, desde os primeiros anos, pode aproximar os alunos aos problemas reais da sociedade, aos quais apliquem os conhecimentos e habilidades adquiridas, de modo a formar uma atitude científica extensível à atividade profissional.

Quanto a este aspecto:

São justamente as habilidades mentais de comparação, julgamento, criação e investigação de problemas que os professores esperam estimular por meio da iniciação científica. Isto porque a participação em atividades de pesquisa estimula a criatividade e curiosidade $e$ incrementa a atitude crítica dos alunos, que desenvolvem uma nova postura em relação ao saber e se tornam mais motivados para aprender ${ }^{17: 22}$.

Nessa perspectiva, o aluno deve sentir apoio e estímulo nos professores, para que possa desenvolver uma atitude positiva frente a determinadas atividades que executa automaticamente. Portanto, torna-se importante que estas tenham a qualidade requerida e, sobretudo, um enfoque investigativo, apresentando a metodologia científica por meio do seu exercício prático.

Dentre os quatro alunos que acharam "pouco importante", apenas um argumentou sua opção, expressando-se do seguinte modo:

[...] Não acho que seja importante, porque, se o fosse, os professores nos ensinariam a fazer desde os primeiros anos. O que eles pedem são trabalhos para pesquisar na biblioteca, os quais devem ter capa, introdução, desenvolvimento, conclusão e bibliografia. É bom porque o ponto é garantido, basta que o apresentemos [...] $\left(A_{24}\right)$.

$\mathrm{Na}$ análise dessa afirmação, é possível inferir que a atividade executada não foi educativa, pois não teve significado para o aluno, tendo em vista sua satisfação girar apenas em torno de nota, fator revelador da incapacidade de refletir sobre as conseqüências do que deixou de aprender.

Corrobora com esse ponto de vista:
Não há limite para o significado que uma ação possa a vir a ter. Tudo depende do contexto de conexões perceptivas em que está situado; o alcance da imaginação para perceber conexões é inesgotáve/18:77.

Em outras palavras, aprender é ser capaz de expressar o conteúdo com as próprias palavras, aplicá-lo a situações concretas da vida e perceber generalizações e casos particulares, apropriandose do conhecimento e usando-o de forma significativa.

Considera-se necessário, então, que o professor, ao solicitar uma pesquisa bibliográfica, decomponha-a nas tarefas que 0 aluno necessita realizar, explicitando sua importância para a formação de determinada habilidade, além de enfatizar que 0 conteúdo não deve limitar-se às informações contidas nos livros. Pelo contrário, o aluno deve desenvolver habilidades de seguir o raciocínio do autor e aplicar critérios para julgar sua adequação a partir de comparações com outros autores e com sua própria opinião e reflexão.

Pode-se, então, dizer que esse aluno assumiu uma atitude passiva em sua vivência, durante os vários trabalhos realizados no curso, demonstrando insuficiente vínculo científico com a atividade investigativa.

\section{Reflexão média:}

Os cinco alunos desta subcategoria, que representam 15,1\% do total, referiram objetivos mediatos para a prática profissional. No entanto, seus argumentos demonstraram limitação de afetividade. Pôde-se perceber isso nos seguintes registros:

\section{[...] Estimularia todo o potencial do aluno, estimulando- o a aprimorar cada vez mais seus conhecimentos na profissão $[. .].\left(A_{g}\right)$.}

Seria muito importante para a formação do enfermeiro, pois adquiriria uma melhor formação científica, para exercer a prática profissional com maior segurança $\left(A_{33}\right)$.

Nota-se, nas citações acima, uma escassez de manifestações afetivas. As opiniões foram reproduzidas de modo formal, podendo significar uma diminuição da capacidade de associar os conhecimentos previamente adquiridos, uma vez que não conseguiram demonstrar solidez de argumentos e fundamentar, com criatividade, suas decisões.

\section{Reflexão boa:}

Os quatro alunos aí inclusos refletiram acerca de sua prática profissional, valorizando não só o conhecimento teórico, mas também o modo de atuar com ele. Observe-se o depoimento:

Acho muito importante, porque propiciaria um conhecimento muito mais científico, que levaria a uma crescente necessidade de investigar, visto que esta é a única atividade capaz de subsidiar tal conhecimento, contribuindo para uma atuação prática fundamentada na descoberta e conseqüente produção do seu próprio conhecimento $\left(A_{27}\right)$.

Percebe-se que o posicionamento acima teve suporte reflexivo e estabelecimento de relações afetivas condicionadas às necessidades profissionais e pessoais.

Pode-se, então, destacar que esse aluno conseguiu perceber o valor e utilidade da atividade, o que não significa que possa aplicá-los de forma eficiente, pois, para tanto, há necessidade de participação em tarefas concretas nas atividades que the 
interessem, das quais compreenda sua relevância e em que se envolva ativamente.

\section{A motivação do aluno para investigar}

A motivação é um conjunto de estados e processos internos da pessoa, que despertam, dirigem e sustentam uma determinada atividade. Esse conceito de motivação parte da premissa de que um aluno motivado é aquele que desperta sua atividade, convertendo seu interesse por certo assunto em ações concretas; dirige seus estudos para metas concretas, procurando eleger um assunto ou uma disciplina que tenha objetivos de aprendizagem congruentes com suas metas pessoais e sustente seus estudos de forma tal que, com persistência, consiga alcançar seus intentos predeterminados ${ }^{19}$.

Dessa categoria, fluíram duas subcategorias: Alunos nãomotivados e Alunos motivados.

\section{Alunos não-motivados:}

As respostas complementares à pergunta revelaram-se expressivas, na medida em que evidenciaram percepções relativas às causas de sua pouca motivação, atribuindo-lhes, basicamente, motivos externos em atinência ao contexto universitário. As razões foram expressas do seguinte modo:

A universidade não incentiva a investigação, portanto esta não é uma prioridade do curso $\left(A_{4}\right)$.

Outro aspecto destacável foi a da ausência de manifestação de esforços de superação voltados para a atividade, que mereceu reflexão relativa ao fraco vínculo do Curso com o componente investigativo e sua influência negativa na motivação do aluno, associada ao processo vivenciado.

No entanto, parte-se do pressuposto de que a preocupação do ensino universitário deve ser a de favorecer a elaboração de estratégias para a aplicação dos conhecimentos adquiridos nas atividades e para a estimulação da criatividade, ao confrontar-se com tarefas cotidianas que exijam resolução de problemas ${ }^{20}$.

A visão limitada dos alunos quanto às suas próprias competências, atitudes e habilidades investigativas foram manifestadas da seguinte maneira:

[...] Não me sinto motivado, porque não sei fazer, acho que por falta de incentivo e respaldo teórico-prático. Talvez se tivesse sido direcionada desde o início [...] $\left(A_{6}\right)$.

Aqui a pesquisa só é trabalhada no último ano, por isso não me sinto motivada para fazê-la, pois não tenho bases científico-metodológicas para tal $\left(A_{29}\right)$.

A autopercepção relaciona-se com os conhecimentos que uma pessoatem sobre ela mesma, e se modifica segundo os acontecimentos quevivem. Corresponde aqui às capacidades reais dos alunos, ou seja, à percepção de sua competência para executar uma tarefa ${ }^{19}$.

0 fato de esses alunos perceberem-se incapazes refletiu em suas atitudes, pois não manifestaram interesse em buscar novas possibilidades para alcançar seus objetivos, o que pode traduzir o medo de enfrentar riscos e errar em novas tentativas.

Muitos alunos não aprendem porque não são motivados adequadamente. Apelando para uma motivação intrínseca, suas metas e interesses não os induzem a se esforçarem para aprender. Existem também alunos que não são motivados porque a aprendizagem não foi significativa e não conseguiram aprender, o que os impediu de experimentar a competência de supor que sabem fazer. A experiência é um dos fatores que mais os estimulam a seguirem esforçando-se ${ }^{19}$.

Um indicador da predominância do componente laboral sobre o investigativo refere-se ao tecnicismo, que aparece vinculado em várias citações, conforme os exemplos que se seguem:

Aqui no curso, aprendemos muitas técnicas específicas da profissão. O resto, como a pesquisa, não é trabalhado. Por isso, não gosto e tenho raiva de ter que fazer TCC, pois não pratiquei antes. Agora, no final do curso, somos obrigados a fazer, mesmo sem saber como [...] $\left(A_{18}\right)$.

0 Curso de Enfermagem nos preparou para sermos enfermeiros e prestar assistência. A pesquisa, antes dessa série, só foi vista sob a forma teórica em duas disciplinas (Metodologia Científica e da Pesquisa). Como posso estar motivado por algo que não sei e me é imposto na última série? $\left(A_{4}\right)$.

A percepção de controle refere-se ao grau de domínio que o sujeito possui sobre o desenvolvimento e as conseqüências de uma atividade que se propõe a fazer. Ela é influenciada pelo modo de perceber as causas do que acontece, as quais podem ser internas (atitudes intelectuais, esforço, interesse, etc.) e externas (dificuldade de uma tarefa, qualidade de ensino, professores, etc. $)^{21}$.

Constatou-se que a motivação dos alunos foi influenciada por situações conflitivas relativas ao contexto do Curso, traduzidas, para eles, como um ensino-aprendizagem, que, aliado às outras características pessoais, impediu-os de detectarem seu valor.

A qualificação do professor foi outro aspecto evidenciado como entrave à motivação de nove alunos desta categoria. A afirmação de que os professores não possuem formação científica consistente para orientar trabalhos de investigação e a indefinição de linha metodológica comum ao corpo docente apareceram nas seguintes citações:

Como eu posso gostar de pesquisa, se não sei fazer e nem os professores sabem? Cada um ensina a metodologia de um jeito, basta ver na apresentação dos TCC. Sempre aparece um dizendo que a metodologia orientada pelo outro está errada. Daí..., mais confusão para a nossa cabeça... $\left(A_{2}\right)$.

[...] Acho que alguns professores que orientam TCC deveriam, primeiramente, fazer um treinamento de metodologia da pesquisa para aprenderem como se faz [...] $\left(A_{28}\right)$.

Foi significativo analisar a percepção dos alunos acerca do saber e da prática investigativa dos professores, uma vez que conduz à necessidade de uma identidade positiva entre discentes e docentes, considerando que estes possuem um papel relevante na motivação dos alunos.

0 desenvolvimento do pensamento ocorre inicialmente em um plano interpsicológico, iniciando-se pela formação de habilidades na interação social, e, em seguida, o interpsicológico passa a ser intrapsicológico ${ }^{4}$. A partir daí, pode-se dizer que, se os professores propiciarem a interação social como uma atividade importante, podem desenvolver os processos psicológicos superiores do pensamento. 
Nessa visão, o professor não é o executor do processo de ensino e nem o usuário do conhecimento, suas ações são exercidas com e sobre o conhecimento, através da interdisciplinaridade, estimulando a percepção dos alunos para buscarem as relações existentes entre os conteúdos, bem como a atitude investigadora.

Por outro lado, se os professores também não se empenham para superarem as dificuldades de aplicar o método científico, não adquirem habilidades. Como ensinar aquilo que não dominam e cuja orientação parece-lhes tão abstrata, frente ao que Ihes foi ensinado teoricamente?

Assim, se os alunos não podem aplicar de forma significativa às questões práticas o aprendido previamente, isso se deve à natureza da situação na qual foi produzido esse conhecimento. Pode-se, então, destacar que a prática docente dos enfermeiros reflete a reprodução de suas vivências como alunos de uma formação tradicional e tecnicista, alijada do componente investigativo.

\section{Alunos Motivados:}

Foi significativa a diversidade de justificativas sobre a satisfação pessoal e precisão nos objetivos profissionais, assim como a ausência de valorização e a presença de critérios eminentemente reprodutivos

Dentre os vinte alunos motivados, quinze limitaram seus argumentos a critérios reprodutivos e não refletiram sobre suas respostas, demonstrando contradições, pois não houve estabelecimento de vínculos afetivos com o processo, assim como as razões argumentadas foram nulas e sem valorizações:

Sou motivada porque sei que a investigação é considerada um avanço no desenvolvimento profissional $\left(A_{31}\right)$.

Somente quatro alunos expressaram seus argumentos baseados em critérios relativos à aplicabilidade social da investigação à práxis da enfermagem, refletindo sobre seus resultados e empenhando-se para conseguirem seus intentos. Expressaram-se através de frases como a seguinte:

[...] Apesar de, somente no último ano, ter sido incentivado a pesquisar, pretendo continuar e aprimorar meus conhecimentos nessa prática, e não parar somente no TCC. Somente assim serei um bom enfermeiro e poderei contribuir para o progresso da ciência, da minha profissão e para a saúde da sociedade [...] $\left(A_{18}\right)$.

0 estado de satisfação é a unidade motivacional na qual se concretiza o sistema de valores afetivos, na medida em que o sujeito sente a iminência de alcançar um resultado e experimenta o desenvolvimento de tal funcionamento. É, na verdade, o que expressa em suas valorizações afetivas. 0 aluno, possuidor de pouco desenvolvimento da atitude motivacional valorativa até a atividade pedagógica, não reflete sobre e nem experimenta satisfação ante a prática profissional futura ${ }^{19}$. As falas seguintes traduzem o que se quis expressar:

[...] As práticas deixam muito a desejar; além do tecnicismo, o curso não oferece oportunidades para outros horizontes. A enfermagem ainda é exercida como uma receita pronta: curativo, injetável, etc., como se só isso bastasse ao enfermeiro [...] $\left(A_{13}\right)$.
Acho que, em parte, principalmente quanto à pesquisa, o aluno a vê somente na $5^{a}$ série, portanto é o primeiro e último contato com a atividade. Como pode adquirir capacidade? 0 sistema de ensino só nos prepara para a assistência [...] $\left(A_{24}\right)$.

O currículo não possibilita que as atividades de administração, ensino e pesquisa sejam vistas como um sistema através de todas as séries $\left(A_{19}\right)$.

Desenvolver a capacidade para investigar impõe não só 0 domínio do método das ciências, alcançado por intermédio da pós-graduação, mas também a prática, a familiarização e a motivação pela atividade investigativa durante a graduação, para que se transforme em aperfeiçoamento constante. Notase pelo histórico da formação do Curso de Enfermagem que o alcance dos objetivos se dá, prioritariamente, em termos de competência técnica para a prática assistencial.

De todo o expressado, pode-se afirmar que os alunos não pesquisam porque o curso não propicia o desenvolvimento das aptidões necessárias para tal. A aprendizagem é reprodutiva, o ensino é tecnicista e não enfatiza o componente investigativo; os trabalhos realizados pelos alunos têm pouco rigor científico e a maioria dos professores apresenta inconsistente formação científico-investigativa tanto para orientar o TCC como para aplicar métodos e técnicas de ensino-aprendizagem que possibilitem o alcance dessa formação pelo aluno.

Relativas aos professores, foram investigadas as seguintes questões: 0 conhecimento sobre habilidades investigativas e 0 seu desenvolvimento lógico durante cada série do curso.

Os resultados das análises demonstraram que $40 \%$ dos entrevistados desconheciam o que eram habilidades investigativas, ou seja, ignoravam as condições que permitem a geração desse saber e os processos determinantes de sua ação. Assim, por exemplo, apontaram habilidades como teoria, leitura, familiarização e prática em sala de aula ou campo de estágio.

Acho que as principaishabilidades que oaluno devese apropriar são a leitura e análise e interpretação de dados $\left(P_{4}\right)$.

Habilidades investigativas? Seria a pesquisa ou a familiarização com esta prática? $\left(P_{7}\right)$.

As habilidades investigativas que os alunos devem ter seriam resumir, resenhar, analisar [...] $\left(P_{2}\right.$ e $\left.P_{9}\right)$.

Outra constatação refere-se à tendência dos professores em citar habilidades de caráter geral como investigativas, atrelada à informação de inexistir continuidade sistemática nas séries seguintes. Nesse sentido, apareceram: ler, resumir, resenhar, etc. Sabe-se, todavia, que a leitura é uma habilidade geral e necessária para a investigação, porém não só para esta.

A problemática foi evidenciada também pela confusão detectada em $60 \%$ dos entrevistados, entre os termos "habilidades" e "etapas investigativas", expressando-se os professores da seguinte forma: exploratória, pesquisa bibliográfica, pesquisa de campo, fazer o projeto e elaborar o TCC.

As habilidades investigativas que o aluno deve adquirir na graduação são a pesquisa exploratória, elaborar o projeto e executá-lo, culminando no TCC $\left(P_{1,}, P_{4}, P_{6}, P_{8}\right)$. 
[...] As habilidades investigativas seriam a exploratória, pesquisa de campo e TCC $[\ldots]\left(P_{3}\right.$ e $\left.P_{5}\right)$.

Outro professor estabeleceu classificações de habilidades sem especificá-las para o caso específico da investigação científica:

Habilidades investigativas? Seriam as habilidades sociais, intelectuais e atitudinais? $\left(P_{8}\right)$.

Um aspecto relevante na fala desses atores (seis professores) foi relativo à falta de tempo, revelando uma desarticulação entre o ensino e a investigação, como se não fossem atividades que se complementem e se interrelacionem, optando, na maioria das vezes, pela primeira, como se o ensino de práticas reflexivas demandasse um tempo muito além dos planejamentos educacionais.

[...] A investigação é muito importante na universidade, mas, para isso, teríamos que ter mais tempo com os alunos e também disponibilidade de carga horária para tal, pois, com o tempo que dispomos, isso é impossível [...] $\left(P_{5} e P_{8}\right)$.

Em apenas um caso houve uma verdadeira concepção do sistema de habilidades investigativas, partindo das aptidões necessárias para apropriar-se da informação através de diferentes fontes, passando pela observação dos fenômenos, elaboração de desenhos, métodos e técnicas de processamento da informação, até as habilidades próprias de generalização, apresentação e comunicação dos resultados.

Pode-se observar também a inexistência de ponderação entre os componentes acadêmicos, laboral e investigativos, uma vez que $70 \%$ priorizaram o acadêmico, posto que, na concepção desses professores, deve-se desenvolver em primeiro lugar a teoria, deixando-se para os últimos anos as aplicações práticas.

Esse entendimento veio somente evidenciar o problema, detectado pelos alunos ao referirem-se aos professores, em relação à dissociação entre teoria e prática existente nas disciplinas e ao insuficiente preparo investigativo dos professores que orientam o TCC.

Do exposto, é lícito dizer que não se pode ensinar aquilo que não se pratica. Para ensinar os alunos a investigarem, os professores necessitam adquirir habilidades relacionadas com a metodologia científica.

Referentes à distribuição das habilidades por séries, as respostas evidenciaram um quase total desconhecimento da maneira correta de manejar o processo de desenvolvimento das habilidades investigativas. Em apenas um caso, deu-se seguimento lógico às ações; todavia, conforme dito anteriormente, entre 0 conjunto de respostas (40\%) que detectaram confusão entre habilidades investigativas e etapas da investigação, $80 \%$ destas últimas organizaram-se segundo uma ordem lógica.

Apesar da unanimidade de que os alunos deveriam desenvolver habilidades investigativas, detectaram-se incoerências nas falas dos entrevistados, ao afirmarem que, somente na quinta série, eles deveriam desenhar e executar um projeto de investigação.

[...] Acho que os alunos deviam ler, resumir e resenhar nos três primeiros anos, na $4^{a}$ série existe a disciplina metodologia da pesquisa, então aí ele aprenderia a fazer um projeto de pesquisa para poder fazer o seu TCC na $5^{\text {a série }[\ldots]}\left(P_{2}, P_{5}\right)$.
Cabe pensar, então, que professores e alunos produzem suas existências a partir do modo como se relacionam com os contextos em que têm experiências, e que os professores, embora variem em suas práticas, precisam compartilhar uma base de conhecimentos que permitam uma atuação comum e consenso na interação entre eles.

Entende-se que todos os professores, desde que devidamente capacitados, podem contribuir para a formação dos alunos na prática investigativa ao organizarem o processo educativo integrando os componentes laboral, investigativo e acadêmico. Note-se que, se só existir o componente acadêmico, o ensino passa a ser escolástico; se só existir o laboral, tende ao pragmatismo; e, portanto, a solução para essa disjunção é dialética: 0 estudo-trabalho. 0 investigativo está presente nas atividades acadêmicas e laborais quando estas se desenvolvem sobre a base científica, por meio da solução de problemas.

Ao cruzarem-se os resultados da análise das respostas dos professores com a dos alunos, pôde-se perceber a ambigüidade dos saberes do corpo docente em relação à temática e ao desenvolvimento de habilidades investigativas. E também quanto à forma como interferem em sua prática cotidiana, na interação com seus alunos e disciplinas, na orientação do TCC e definição de metodologias. 0 mesmo ainda pode ser dito quanto às tomadas de posições e sugestão de mecanismos para superação, seja na prática docente ou na gestão administrativa.

Finalmente, pôde-se inferir a tendência de muitos professores em não perceberem a relação entre o ensino e a pesquisa, entre a teoria e a prática, entre o laboral e 0 investigativo, entre os objetivos, os conteúdos, as ações e as tarefas necessárias para a execução da atividade. Embora tenha sido consenso entre eles a necessidade de devolver à sociedade um profissional mais capacitado, poucos se referiram à via mais eficaz para lograr o alcance desse objetivo.

Essa constatação vem demonstrar que os professores percebiam o problema e as necessidades sociais, entretanto, por não estarem familiarizados com o sistema de ações e tarefas que precede à formação e ao desenvolvimento das habilidades, não conseguiam sugerir uma organização lógica no contexto das séries.

\section{CONSIDERAÇÕES FINAIS}

A educação em enfermagem constitui a base essencial para edificar o progresso da profissão. Seu desenvolvimento, atualização e informação reclamam por transformações intensas, que dêem como respostas o avanço na formação dos futuros profissionais.

É desejável que o ensino da enfermagem se dê em um contexto multidisciplinar onde, por meio do estudo científico dos problemas encontrados no trabalho de assistência, possa desenvolver aprendizagens significativas, capacidade crítica, capacidade de leitura nas diferentes áreas do saber e a aquisição de habilidades investigativas, com vistas a uma prática cientifica atualizada.

Faz-se necessário consolidar, no Curso de Enfermagem da UEPA, um modelo que propicie a aquisição de habilidades necessárias para que os futuros profissionais possam investigar. Esta é a forma de enriquecer tanto a prática do professor como o próprio curso, uma vez que conduz à projeção da profissão e à solução de problemas de saúde do meio onde está inserido. 
Nesse sentido, formar o espírito científico requer criar condições favoráveis desde o ingresso do aluno até o último ano no curso, garantindo um terreno fértil para que as sementes dêem frutos, ou seja, instigar e promover o desenvolvimento das habilidades e competências investigativas em temas transversais e específicos relevantes.

Dentre as principais inconsistências encontradas, tem-se a vinculação temática da investigação científica exclusiva ao TCC, o que reflete ser este o único e último ensaio científico dos alunos do Curso. Some-se a isso o fato de que o componente investigativo é alijado dos componentes acadêmico e laboral do curso, e ainda o ensino tecnicista e a dissociação teoria/prática. Todos esses são fatores que contribuem para a pouca motivação dos alunos quanto à realização de investigações científicas no curso.

Com relação aos professores, identificou-se que possuem uma formação científico-investigativa inconsistente para orientar o TCC e aplicar métodos e técnicas de ensinoaprendizagem que possibilitem a realização de atividades investigativas. Destaca-se também a indefinição quanto a uma metodologia investigativa comum a todos os professores, e a pouca familiarização destes com as habilidades investigativas e sua operacionalização durante as séries do curso.

\section{Referências}

1. Palmeira IP. A investigação científica no Curso de Enfermagem da Universidade do Estado do Pará: da análise à proposta. [dissertação de mestrado] Belém (PA): Universidade do Estado do Pará/UEPA; Cuba /IPLAC; 2000.

2. Lei n ${ }^{\circ}$ 9394, de 20 de dezembro de 1996. Lei de Diretrizes e Bases da Educação Nacional. Brasília(DF): MEC; 1996.

3. Leontiev AN. Actividad, conciencia, personalidade. Ciudad de La Habana (CU): Pueblo y Educación; 1983.

4. Vigotsky LS. A formação social da mente. São Paulo (SP): Martins Fontes; 1998.

5. Luria AR. A mente e a memória. $2^{\mathrm{a}}$ ed. São Paulo(SP): Martins Fontes; 2006.

6. Libâneo JC. A didática e a aprendizagem do pensar e do aprender: A teoria histórico-cultural da atividade e a contribuição de Vasili Davydov. Rev Bras Educ 2004 set/dez; 36 (27): 5-24.

7. Kozulin A. 0 conceito de atividade na psicologia soviética: Vigotsky, seus discípulos, seus críticos. In: Daniels H. Uma introdução a Vygotsky. São Paulo(SP): Loyola; 2002.

8. Saviani D. 0 espaço acadêmico da pedagogia no Brasil: perspectiva histórica. Paidéia: cad psicol educ 2004 maio/ago; 14 (28): 113-24.

9. Vasconcellos CS. Currículo: a atividade humana como princípio educativo: para além da prática disciplinar instrucionista. Rev Educ AEC 2006 jul/set; 35 (140): 27-46.

10. Daniels H. Vygotsky e a pedagogia. São Paulo (SP): Loyola; 2003.
0 momento atual aponta para um esforço contínuo de superação das dificuldades inerentes à investigação científica, levando em consideração as limitações físicas, humanas e institucionais; tem havido avanços significativos nesse campo, como pode se observar a seguir: foi criado o TCD (Trabalho de Conclusão de Disciplina); melhoria na qualidade dos TCCs; criação de vários cursos de especialização e conseqüente aumento na produção científica da instituição; melhoria da titulação docente com a oferta de cursos de mestrado em parceria com a UEPA: Convênio com IPLAC/Cuba e Interinstitucional (MINTER)/UEPA-UFRJ, totalizando a formação de 29 mestres; maior envolvimento dos docentes em atividades de orientação e de pesquisa e extensão; formação de grupos de pesquisa no Curso; dentre outros.

Assim, formar e desenvolver habilidades investigativas no Curso é um processo que será construído em duplas, triplas ou múltiplas vias. Após sete anos da realização desse estudo, a reflexão constante sobre pontos importantes na formação do enfermeiro tem sido a prática dos docentes do Curso de Enfermagem da UEPA, resultando em conquistas paulatinas em direção à formação do profissional que se acredita estar sendo mais bem preparado às exigências do novo século e da Lei de Diretrizes e Bases da Educação no Brasil.

11. Zayas CA. La escuela en la vida. 6 ${ }^{\text {a }}$ ed. Cochabamba(CO): Kipus; 2004. 12. Leontiev NA. Sobre o desenvolvimento histórico da consciência. In: 0 desenvolvimento do psiquismo. Lisboa (PT): Horizonte Universitário; 1978.

13. Lipman M. 0 pensar na educação. Tradução de Ann Mary Figueira Perpétuo. $7^{\text {a }}$ ed. Petrópolis (RJ): Vozes; 1999

14. Triviños ANS. Introdução à pesquisa em ciências sociais: pesquisa qualitativa em educação. $4^{a}$ ed. São Paulo (SP): Atlas; 1995.

15. Minayo MCS. Ciência, técnica e arte: o desafio da pesquisa social. In: Deslandes SF, Cruz Neto 0, Minayo MCS, organizadores. Pesquisa social: teoria, método e criatividade. $23^{\mathrm{a}}$ ed. Petrópolis (RJ): Vozes; 2004.

16. Maldonado LA, Paiva EV. A iniciação científica na graduação em nutrição: possibilidades e construções para a formação profissional. In: Calazans J, organizadora. Iniciação científica: construindo o pensamento crítico. São Paulo (SP): Cortez; 1999.

17. Viau R. Pedagogies en développement: problématiques et recherches. Saint Lorent(CA): Boeck Université [on-line] 1994; [citado 13 maio 1999]; Disponível em: http://www.pangea.otg/org/espiral/ hiperespiral/himoviau.html

18. Splitter L, Sharp AM. Uma nova educação: a comunidade de investigação em sala de aula. São Paulo (SP): Nova Alexandria; 1999.

19. González V. Motivación profesional y personalidade. Habana(CU): Universidad Mayor Real y Pontificia de San Francisco Xavier; 1994.

20. Demo P. Pesquisa: princípio científico e educativo. $12^{\mathrm{a}}$ ed. São Paulo(SP): Cortez; 2006.

21. Tapia JA, Fita EC. A motivação em sala de aula: o que é, como se faz. São Paulo(SP): Loyola; 2001. 